\title{
Bronchial Brush Biopsy
}

National Cancer Institute

\section{Source}

National Cancer Institute. Bronchial Brush Biopsy. NCI Thesaurus. Code C93016.

The use of a brush to obtain tissue samples from one or more bronchi. 